\title{
POP KONTEMPORER REMAJA SEBAGAI MEDIA BAGI GENERASI MILENIAL
}

\author{
Nuriyah Nazilah1 \\ 1)Institut Agama Islam Sunan Kalijogo \\ 1)NuriyahNazilah283@gmail.com
}

\begin{abstract}
Abstrak. Komunikasi adalah proses penyampaian suatu informasi,atau pesan kepada seseorang yang akan membekas pada jiwa tiap individunya, tentu komunikasi ini yang menjadi bagian penting dalam media dakwah. Media dakwah adalah alat yang digunakan sebagai perantara dalam mencapai tujuan dakwah.dalam menyampaikan pesan dan terhadap penerima dengan lebih memanfaatkan media untuk mencapai suatu keberhasilan, maka media ini menjadi sangat penting, terlebih pada era zaman sekarang para remaja yang tidak lepas untuk bermain di social media. Fungsi media dakwah adalah sebagai perantara penyampaian pesan dalam kegiatan dakwah yang bertujuan untuk mendukung aktivitas dakwah agar lebih efektif dan efisien dalam menyampaikan nilainilai islam kepada remaja.Karena itu, tidak mungkin dakwah tersebut sukses tanpa adanya media yang membantu menyukseskan kegiatan dakwah. Makin banyak menguasai media penggunaan media dalam kegiatan dakwah, maka semakin mengantar kepada keberhasilan dan kesuksesan dalam melaksanakan dakwah. Media yang digunakan untuk menyampaikan dakwah yakni media cetak, media elektronik, televisi, radio, majalah, tabloid, internet dan media lainnya. Akan tetapi kini yang lebih popular dan banyak digandrungi oleh remaja adalah media internet. Karena media internet ini yang mengungkap isu-isu kontemporer lalu dijadikannya sebagai materi dakwah agar tetap dalam nilai-nilai yang berada pada islam dan tidak ada kesesatan. Karena kecenderungan hidup manusia pada abad ini memiliki gaya hidup yang lebih mengandalkan pada hiburan, makanan, dan pakaian. Jadi lebih mengandalkan hidup pada kenikmatan-kenikmatan yang bersifat praktis dan pragmatis menyenangkan, bisa dirasakan pada saat ini yang lebih positif. Sehingga mengabaikan aspek-aspek yang lebih bersifat substantif dan orientasi pada isi bukan bentuk. Dalam kontemporer ini remaja bisa menggunakan pop kontemporer untuk berdakwah agar para pembaca atau penonton tidak bosan dan tetap menambah ilmu mereka terhadap nilai-nilai islamnnya.
\end{abstract}

Kata Kunci: Media Dakwah, Pop kontemporer, Remaja

Abstract. Communication is the process of delivering information, or messages to someone who will imprint on the soul of each individual, of course this communication is an important part in the media of da'wah. more use the media to achieve a success, then this media becomes very important, especially in today's era of teenagers who can not be separated to play on social media. The function of da'wah media is as an intermediary for delivering messages in da'wah activities. Which aims to support da'wah activities to be more effective and efficient in conveying Islamic values to teenagers. Therefore, it is impossible for da'wah to be successful without the existence of media that help make da'wah activities successful. many master the media use of media in da'wah activities, it will increasingly lead to success and success in carrying out da'wah. The media used to convey da'wah are print media, electronic media, television, radio, magazines, tabloids, internet and other media. But now what is more popular and much loved by teenagers is the internet media. Because this internet media reveals contemporary issues and then uses it as propaganda material so that it remains in the values that are in Islam and there is no misguidance. This century has a lifestyle that relies more on entertainment, food, and clothing. So it relies more on living on pleasures that are practical and pragmatic, fun, can be felt at this time which is more positive. 
Thus ignoring aspects that are more substantive and orientation on content not form. In this contemporary era, teenagers can use contemporary pop to preach so that readers or viewers do not get bored and continue to increase their knowledge of Islamic values.

\section{Keywords: Da'wah Media, Contemporary Pop, Teenagers}

\section{PENDAHULUAN}

Kualitas hidup kita ditentukan dengan bagaiamana cara kita berkomunikasi ,Karena hubungan kita dengan sesama manusia dapat ditingkatan dengan lebih memahami dan memperbaiki komunikasi yang kita lakukan setiap hari. Dengan kita lebih memahami arti dari komunikasi kita bisa membentuk rasa saling pengertian, memelihara kasih sayang, menyebarluaskan pengetahuan, dan melestarikan peradaban.Dengan demikian komunikasi adalah suatu alat atau sarana yang dimanfaatkan sebagai alat suatu proses membangun hubungan antar sesama melalui pertukaran informasi untuk menguatkan sikap dan tingkah laku orang lain serta berusaha mengubah dan mempengaruhi sikap dan tingkah laku tersebut.

Media menjadi hal penting dalam kehidupan. pada perkembangan terkini, media menjadi komoditas khususnya dalam Komunikasi dakwah. Pengelola produk informasi yang akan diberikan pada masyarakat dalam hal ini diperankan oleh media. Penggunaan media menjadi sebuah cara yang efektif dan efisien dalam menyampaikan informasi, termasuk didalamnya informasi keagamaan untuk kepentingan dakwah. Dari sisi Da'i penggunaan media komunikasi ini dapat memperluas Mad'u dakwah. dengan ini, tingkat penyebaran nilainilai agama menjadi luas. berdasarkan pendapat Gerlach \& Ely dalam Arsyad secara garis besar media meliputi manusia, materi dan lingkungan yang membuat orang lain memperoleh pengetahuan, keterampilan atau sikap. jika berpegangan pada pendapat terakhir, maka pendakwah, kitab suci Al-Quran dan hadis yang sedang didiskusikan, suasana ,pelaksanan dakwah, merupakan media dakwah.Demikian juga berati tidak ada dakwah tanpa media. (Gerlach \& Ely (2006:h.3)

Seiring dengan perkembangan kesadaran keagamaan masyarakat, kata Dakwah menjadi semakin sering disebut dalam berbagai diskusi keagamaan. terlebih pada perkembangan zaman saat ini, banyak para remaja yang mempunyai inovasi untuk mengembangan dakwah menjadi bervariasi. Berdasarkan pendapat Prof.Dr.Moh Ali Aziz,M.ag. “Terkait dengan dakwah sebagai proses penyampaian ajaran islam, ada tiga hal yg mengajarkan yaitu kesetaraan gender dalam dakwah, kewajiban dakwah, dan pesan dakwah sesuai dengan keadaan Mad'u (penerima dakwah)." (Prof.Dr.moh Ali Aziz M.ag 2014:h.2).Dakwah merupakan perintah Allah langsung kepada tiap hambannya, agar menjadi Khoiru Ummah (umat terbaik). Dakwah juga 
denyut nadi islam, islam dapat bergerak dan hidup karena dakwah. Untuk itu Dakwah sangat penting untuk kita terus lakukan dan kembangan.sebagaimana yang telah diperintahkan Allah untuk selalu berdakwah dan mengikuti jejak Rasulullah SAW.

Pop kontemporer adalah sebuah popularitas yang keberadaannya berkaitan erat dengan perkembangan seni yang terpengaruh dampak modernisasi dan tidak memiliki aturan konvensional. Pop kontemporer ini juga lazim menyandang sebutan yang baru saja muncul, karena sebagai konsekuensi yang keberadaannya selalu mengedepankan sebuah era dan juga dituntut untuk selalu menghadirkan sebuah karya baru yang belum pernah diciptakan sebelumnnya.seperti contoh yakni seni music kontemporer istilah music kontemporer ini pada dasarnya seni music modern karena jenis music kontemporer ini music masa kini yang baru diciptakan sebelumnnya

\section{METODE PENELITIAN}

Dalam penulisan artikel ini Sumber data merupakan hal yang wajib diperoleh dalam penelitian, karena melalui sumber data yang tepat maka penelitian akan berhasil dengan baik ${ }^{1}$. Maka untuk mendapatkan data yang tepat peneliti menggunakan metode penelitian kualitatif sebagai prosedur penelitian yang menghasilkan data berbentuk deskriptif yang berupa kalimat dan kata-kata tertulis atau lisan dari orang-orang berdasarkan objek penelitian yang diamati, yakni tentang pop kontemporer remaja sebagai media bagi generasi milenial. Dalam penelitian kualitatif, bentuk data berupa rangkaian kalimat atau narasi dari subjek atau responden penelitian yang diperoleh melalui suatu teknik pengumpulan data. Berbagai data tersebut kemudian dianalisis sehingga diperoleh berbagai temuan yang akan dapat diuraikan oleh peneliti sebagai kajian dalam pembahasan.

\section{PEMBAHASAN}

\section{Berbagai Media Dakwah di Indonesia}

Media dakwah di Indonesia berkembang seiring dengan kemajuan teknologi, yang telah menjadi bagian penting dalam kehidupan sehari-hari. Karena di era sekarang dimana teknologi bergerak sangat cepat yang telah mempengaruhi generasi muda yang semakin lincah dalam menggunakan social media sebagai media komunikasi. Inilah yang menjadi dasar seorang da'i

${ }^{1}$ Setiadi, Gatut, and Nurma Yuwita. "PENGEMBANGAN MODUL MATA KULIAH BAHASA INDONESIA MENGGUNAKAN MODEL ADDIE BAGI MAHASISWA IAI SUNAN KALIJOGO MALANG". Akademika : Jurnal Manajemen Pendidikan Islam 2, no. 2 (December 3, 2020): 200-217. Accessed May 2, 2021. https://ejournal.iaiskjmalang.ac.id/index.php/akad/article/view/207. 
untuk mengembangkan dakwah melalui media yang disajikan semenarik mungkin agar mudah dipahami oleh masyarakat saat ini. Karena masih belum banyak memahami bagaimana berdakwah terutama bagi generasi milenial yang menggunakan social media sebagai media dakwah. Untuk itu media dakwah tidak cukup jika memakai media tradisional saja seperti melalui ceramah dan pengajian-pengajian yang masih menggunakan media dakwah dengan mauidhoh hasanah (oral)

Perkembangan tatanan kehidupan masyarakat yang semakin komplek dan pertumbuhan semakin pesat sebagai dampak kemajuan ilmu dan teknologi, khususnya teknologi komunikasi mennuntut adanya pengembangan serta pembinaan keagamaan sebagai pondasi kehidupan melalui media elektronik dan internet berupa siaran keagamaan yang lebih berkualitas dan sesuai dengan tuntutan era globalisasi. Oleh sebab itu para generasi milenial harus mengetahuai berbagai macam media dakwah agar lebih mengetahui srategi dakwah dan sasaran dakwah. Hal ini merupakan tantangan bagi generasi milenial khususnya para da'i, karena Indonesia adalah Negara demokrasi dengan perkembangan medianya lebih kearah bisnis sehingga sulit dikendalikan atau dikontrol dari pihak luar para da'i.

Berdasarkan pendapat Amin " Maraknya media sebagai sarana komunikasi massa dan alat pembentuk opini public di era infromasi sekarang ini para da'i, aktivis dakwah dan umat islam terkenal kewajiban secara syari melakukan dakwah bil lisan, bil hal, dan bil qalam para juru dakwah memanfaatkan berbagai media yang ada untuk mengembangan infromasi dakwah. Melihat keinginan yang dimiliki oleh media massa dalam dunia komunikasi, menurut para da'i yang mengerti dan memahami bidang media agar menggunakan kesempatan ini dengan kemampuan yang dimiliki untuk mentransformaasikan ajaran islam kepada seluruh umat manusia dimuka bumi ini." 2

Dakwah di era globalisasi diperlukan pola-pola penyampaian dakwah islam yang tidak lagi menuntut para masyarakat hadir dalam kajian dakwahnya. Salah satu solusinya yakni dakwah disampaikan melalui media teknologi inrformasi. Dengan adanya media teknologi infromasi ini akan mengantarkan pesan-pesan dakwah sampai menyentuh para mad'u yang beragam nuansa dan suasana. Dengan begitu, dakwah akan terus berjalan ,meskipun para mad'u tidak mempunyai kesempatan hadir dalam kajian dakwah. Dakwah yang disampaikan media teknologi infromasi ini juga akan tetap ada dan datang dimananpun kalian berada. Karena bisa menikmati materi dakwah islam tanpa harus meninggalkan pekerjaan, acaran

\footnotetext{
${ }^{2}$ Amin, Ilmu Dakwah, ( Jakarta:Kencana). Hal 255.
} 
keluarga. Adanya media teknologi informasi yang mampu untuk kelangsungan berdakwah dan media ini akan mempermudah dakwah agar bisa sampai langsung kepada mad'u.

Ada berbagai macam media dakwah yang harus diketahui oleh seorang da'I agar infromasi dan pesan dakwah tersebut dapat menghasilkan tujuan dakwah yang dharapkan. Diantaranya:

1. Media audio visual media yang berupa audio visual seperti televisi dan film. Media ini dapat digunakan untuk menerangkan secara jelas idea atau isi pesan dakwah dengan menggunakan metode popular saat ini, seperti cerita atau kisah yang diperankan oleh seorang influencer. Media televise ini juga digunakan sebagai media dakwah secara inhern yang mana melalui muatan nilai yang terkandung dalam program tv. Seperti Dalam film ayat ayat cinta yang dibintai Fedi Nuril dan Rianti Catwright dengan topic cerita tentang kesetiaan pada kemanusiaan, film ketika cinta bertasbih, perempuan berkalung sorban, atau sinetron tukang bubur naik haji. Nilai-nilai yang ditampilkan beberapa film tersebut mengandung ajaran islam dan menyentuh religi islam. Meskipun fungsi dakwah dalam televise ini masih minim, tidak menutupi kemungkinan mad'u untuk mencerna isi pesan dakwah dalam program tv, namun dengan segala unsurnya mulai dengan mngeluarkan tayangan acara-acara dengan kemasan nilai -nilai agama islam, maka agaa islam dalam sosialnya akan menggema melalui dakwah dimedida televise.

2. Media visual. Media visual yang dimaksud seperti majalah pop. Majalah punya peran sentral (tengah-tengah) dalam penyampaian islam. Karena memadukan dua pendekatan sekaligus, diantaranya pendekatan tulisan dan visual. Majalah pop tentang dunia remaja sementara ini masih menguasai liputan-liputan dan dirancang buat dunianya. Seperti persoalan cinta, konsumsi, dan fashion yang selalu menjadi topik-topik yang paling diminati. Namun dalam majalah pop memiliki daya tarik untuk berdakwah yakni yang pertama kode romance/percintaan yang mana percintaan bisa di berikan nilai nilai islamnya jadi tinggal menambahi hadist kasih sayang dan kecintaan rasul pada umatnya. Kedua Kode kehidupan personal juga bisa dimasuki nilai-nilai islam seperti yang sampaikan rasul jika kehidupan ingin damai dan tentram maka harus berpegang pada $\mathrm{Al}$ quran dan hadist nabi SAW. Dan yang ketiga Kode fashion dan kecantikan yang juga bisa dimasuki nilai islam yang mana dalam islam dituntut seorang wanita muslim untuk tidak tabarruj atau berlebihan dalam menggunakan make up dan tidak berglamour dalam memakai pakaian. Dari tiga kode daya tarik inilah yang akan menjadikan media majalah pop sebagai pemyampaian media efektif di generasi milenial. Perihal penyampaian pesan- 
pesan dalam islam melalui majalah, pertama harus memperhatikan kaca pada majalahmajalah pop sebagaimana tersebut dimuka adalah bagaimana memosisikan pesan-pesan islam memasuki segmen pemasaran dakwah. Bagaimana remaja sholihah misalnya, tidak hanya kata-kata saja yang keluar dari mulutnya, tapi juga terpampang jelas dalam majalah pop. Kata saleh tidak hanya terpampang pada Al-quran yang suci dan kitab kuning saja, tetapi juga terpampang dalam majalah yang putih, juga berwarna dan "tidak suci" sehingga mudah disentuh oleh siapa saja. Dan mudah dkaji dimanapun tanpa harus memiliki wudhu. Media dakwah semacam ini buka saja mengakrabkan dunia islami dengan dunia manusiawi, lebih dari itu, islam memang harus membumi dan konteks apapun. Inilah gambaran nilai aktuaisasi islam di majalah pop sebagai rahmat bagi semesta alam.

3. Media music pop. Media seni music ni juga termasuk media dakwah yang berkembang pesat di Indonesia. Karena banyak sekali orang yang mengcover lagu barat untu dijadikan penyampaian dakwah islam. Dan tak hanya mengcover saja namun ada yang menciptakan music religi untuk menyampaikan pesan ajaran islam seperti lagi dibuat oleh band Ungu yang berjudul Bismillah Cinta, Opick yang berjudul Tombo Ati dan masih banyak lagi seorang penyanyi Indonesia yang mengcover lagu religi untuk dijadikan bahan penyampaian agama islam.

Tidak diragukan lagi bahwa music Indonesia telah merajai hiburan ditanah air dan dunia hingga detik ini. Perihal music pop, semiotikus mazhab Frankfrut Theodor Adorno dalam esainya yang sangat berpengaruh on populer music seperti berdasarkan pendapat Jhon Storey (dalam buku Acep Aripuddin) "membuat tiga pernyataan spesifik tentang music pop. Pertama music pop "distandardisasi”, yaitu meluas mulai segi-segi umum hingga segi-segi khusus, sekali pola music atau lirikan sukses, ia dieskploitasi hingga mngalami komersial yang memuncak dan sampai pada"Kristialisasi standard". Selain itu detail-detail dari satu lagu pop bisa saling diperukarkan dengan detail-detail lagu pop lainnnya. Kedua kata adorno bahwa music pop mendorong pendengaran pasif. Konsumsi music pop senantiasa pasif dan repetitive yang menegaskan dunia sebgaimana adannya. Apabila music serius dimainkan untuk kesenangan imjinasi, yang menawarkan dunia sebagaimana seharusnya, maka music pop punya korelasi non-produktif dengan kehidupan di koantor dan di pabrik. Ketegangan dan kebosanankerja mengantar laki-laki dan perempuan pada penghindaran terhadapn penggunaan energi fisik dan mental pada waktu luangnya. Dan yang ketiga kata adorno adalah klaim bahwa music pop beroperqsi seperti "konsumen social". Fungsi social-psikologisnya adalah meraih penyesuaian 
fisik dengan mekanisme kehidupan saat ini dalam diri konsumen music pop. Penyesuaian ini memanifestasikan dirinya sendiri dalam dua tipe social-psikologis utama perilaku massa, tipe penurut yang ritmis dan tipe emosional". ${ }^{3}$ Upaya melakukan penyampaian pesan nilai-nilai ajaran islam melalui media music pop dilakukan karena identic dengan kehidupan remaja, bahwasannya para remaja sebagai orang yang lugu yang diekspoitasi oleh music pop yang membuat social-psikologisnya menjadi penurut yang mana sudah dijelaskan pendapat dari jhon storey diatas. Hingga akhirnya para remaja mencerminkan sikap dan sentimentnya yang telah dirasuki oleh media music pop. Upaya ini yang menjadi upaya composer dan pengarang lagu agar mampu menulis dan mendendangkan lagu mengikuti dimensi para remaja dan masyarakat. Untuk melahirkan nasyid-nasyid pop atau melahirkan music-musik pop religious.

Dari ketiga media dakwah yang merupakan cara yang dilakukan para da'I untuk menyampaikan isi pesan dakwah kepada mad'u secara efektif untuk media dakwah di Indonesia, yang merupakan masyarakatnya dinamis sehingga media dakwah ini dipakai untuk menanamkan nilai-nilai ajaran islam secara luas. Media dakwah unsur yang paling penting diperhatikan dalam aktivitas dakwah. Macam-macam media sebagai jembatan demi perkembangan tujuan dakwah. Pesan dakwah yang tepat yakni bisa membimbing manusia menuju moralitas yang baik.

\section{Evolusi Pop Kontemporer}

Peradaban menuju pop kontemporer ini sama dengan halnya bagaimana pop kontemporer bisa ada pada budaya Indonesia dan asal muasal pop kontemporer. Perlu kita ketahui bahwa kontemporer ini berasal dari budaya luar yang diadopsi oleh masyarakat Indonesia dengan diartikan secara luas dan beragam. Tentu kontemporer ini masih menjadi perdebatan antara ahli seni music Indonesia dan masyarakat barat. Para ahli seni music berusaha untuk tidak ada lagi perdebatan sengit diantaranya, dengan membuka pertemuanpertmuan lokakarya dan seminar.

Kata pop sendiri berasal dari kata yang dicetuskan pertama kali oleh pengamat ahli seni music yang berkebangsaan inggris, Lawrence Alloway. Suatu aliran music populer yang dapat dimainkan oleh band atau perorangan. Music pop ini selalu berorientasi yang menuju pada para pemuda yang mana music pop ini lirik lagunya mudah dipahami dan sederhana bahkan mudah dinyayikan dan juga dihafal yang sesuai dengan pasar mudanya. Misal seperti music

${ }^{3}$ Acep Aripuddin (Jhon Storey), Cultrul Studies Dan Kajian Budaya pop, (YogyakartaBandung:Jalasutra). Hal 42. 
pop saat ini yang berjudul "kepastian" oleh Aurelie Hermansyah, dan "tak sanggup melupa" oleh Ziva Magnolya.

Menurut pendapat Djojosudarmo, Maryanto (2000) “Istilah kontemporer sendiri berasal bahasa inggris "contemporary" yang berarti apa-apa atau mereka yang hidup pada masa yang bersamaan". ${ }^{4}$ Artinya kontemporer ini seni pada masa saat ini atau kekinian karena diciptakan pada masa yang bersamaan dengan dunia sekarang secara umumnya. Tetapi juga ada yang memnafsirkan istilah kontemporer ini lebih dikaitkan dengan keberadaaan wujud karya seni yang orientasinya berbeda dengan prinsip-prinsip seni modern dan seni klasik yang sudah mapan. Seperti pendapat yang disampaikan oleh Arthur Danto dalam bukunya After The End Of Art (1995 Hlm 10) " contemporary its most obvious sense means simply what is happening now: contemporary art would be the aart produced by our contemporaries. But as the history of art has internally evolved, contemporary has come to mean an art produced withn a certain structure of production never, I think seen before in the entire history of art. So just as "modern" has coe to dente a style and even a period and not just recent art, "contemporary art has come to designate something more than simply the at of present moment". Aritinya: "Kontemporer pengertiannya yang paling jelas berarti apa yang terjadi sekarang: seni kontemporer akan menjadi seni yang diproduksi oleh orang-orang sezaman kita. Tetapi karena sejarah seni telah berkembang secara internal, kontemporer telah menjadi seni yang diproduksi dengan struktur produksi tertentu, saya pikir tidak pernah terlihat sebelumnya dalam seluruh sejarah seni. Jadi, sebagaimana "modern" memiliki makna gaya dan bahkan periode dan bukan hanya seni barubaru ini, "seni kontemporer telah datang untuk menunjuk sesuatu yang lebih dari sekadar saat ini". ${ }^{5}$ Jadi istilah kontemporer ini mencakup sangat luas dan beragam sehingga munculya suatu perdebatan itu wajar karna pengertian yang beredar di masyarakat ini mempunyai rasionalnya masing-masing dan lebih memandang bahwa seni rupa kontemporer berarti seni rupa modern. Misal seperti instalasi, video art, dan performance art.

Pop kontemporer menjadi suatu budaya pada bagian seni music dikalangan masyarakat milenial zaman sekarang, karena akan banyak dikonsumsi oleh masyarakatnya, tidak hanya dikonsumsi saja namun juga di produksi oleh beberapa masyarakatnya. Kelahiran budaya pop kontemporer juga berasal dari industry seni music popular yang dikembangan oleh beberapa orang sehingga memengaruhi masyarakat lainnya.

\footnotetext{
${ }^{4}$ Djojosudarmo, Maryanto, Apresiasi Karya Seni Modern dan kontemporer, (Jakarta:Balai Pustaka). Hal 41.

${ }^{5}$ Arthur Danto, After The End Of Art, ( Princeton University Press:Amerika Serikat). Hal 10.
} 
Menurut Yoshepa Pusparisa "Word Economic Forum (WEF) dan PRICEWATERHOUSECoopers (PwC) dalam laporannya menyebut sejak 2019 rekaman dalam pelbagai bentuknya, unduhan digital, dan gim mendominasi sumber pendapaatn industry music global. Menggeser sumber penampilan langsung atau konser yang sebelumnya selalu mendominasi pemasukan industry. WEF dan PwC memproyeksikan pada 2019 rekaman menyumbang US\$ 28,8 milar atau Rp 406,1 triliun dengan kurs Rp 14.100/US\$ terhadap total pendapatan industry music dunia. Sedangkan, konser menghasilkan lebih sedikit: US\$ 27 miliar yang setara dengan $\mathrm{Rp} 380,7$ triliun. Tren ini diperkirakan akan terus meningkat di masa mendatang. Indonesia berada pada posisi ketujuh pasar music digital terbesar di Asia dengan potensi pendapatan mencapai US\$ 21 juta pada 2015 ". 6

Perkembangan seni music pop kontemporer akhir-akhir ini semakin meningkat, dan banyak sekali ragam seni music kontemporer yang dikembangkan oleh remaja milenial dan para pencipta music klasik pun juga tak mau kalah, musisi klasik juga merenovasi music klasiknya agar menjadi kalangan music kontemporer yang mapan. Ditahun 2020 menjadi pukulan keras bagi industry music pop kontemporer karena sejak awal tahun 2020 pandemi Covid-19 mulai mewabah kalangan masyarakatnya. Yang menjadikan adanya pembatasan untuk bergerak agar memutus rantai penularan pandemic covid-19 ini. Akhirnya pembuatan konser music pop kontemporer ini menjadi batal missal sepert konser gelaran Synchronize yang sedianya pada oktober lalu. Di sisi lain, kondisi yang tidak tau kapan berakhirnya pandemi covid-19 ini, akhirnya para musisi mengembangkan seni music kontemporer ini menggunakan music digital, missal seperti aplikasi spotify dan platform lainnya. Dari sini penggunaan aplikasi spotify ini smakin meningkat penggunaannya. Mnurut Yoshepa Pusparisa " pada kuarta II-2020, terdapat 299 juta pengguna aktif platform tersebut atau naik 4,5\% disbanding kuartal sebeblumnnya. Jumlah pelanggan berbayarnya pun meninkat 6,2\% menjadi 138 juta pengguna”. Yoshepa Pusparisa, dalam Analisis Data “Wajah baru Industry Musik Di Era Digital”, 21 Desember 2020,11.28 WIB.

Setelah pandemik covid-19 ini usai mungkin akan banyak peningkatan di music pop kontemporer ini, karna konser virtual yang digelar oleh BOLD MUSIC VIRTUAL CONCERT pada tanggal 19 Mei 2021 pada pukul 20.00-22.00 WIB yang dibintangi oleh Fiersa besari dan kawan-kawannya di streaming youtube LAzone.ID ini cukup banyak sekali views nya. Nah

${ }^{6}$ Yosepha Pusparisa, Analisis Data Wajah Baru Industri Musik Di Era Digital, 21 Desember 2020. 11.28WIB. 
apalagi jika pandemic covid-19 ini usai mungkin akan banyak sekali pengunjung sebuah konser yang digelar secara offline, dan jangkauan pengunjung bisa luas dan tetap eklusif.

Evolusi pop kontemporer ini menjadikan arti sempit yakni menjadi dasar seni music kontemporer dikalangan masyarakat milenial yang semakin berkembang. Karena dari beberapa ragam, pengaruh dan peristiwa yang membuat pop kontemporer ini menjadi seni music pop kontemporer. kondisi pop kontemporer ini yang membuat media dakwah semakin berkembang terutama pada zaman milenial saat ini. Mad'u bisa menikmati dakwah dengan berbagai alunan lirik music yang mudah dipahami dan juga da'i yang lebih mudah untuk memberikan dakwah islam lewat pop kontemporer.

\section{Pengaruh Remaja pada Musik Pop Kontemporer}

Music pop kontemporer yakni salah satu seni music yang berpengaruh besar dikalangan pasar mudanya, dan music pop kontemporer ini suatu ungkapan kesenian yang mencerminkan kebudayaan masyarakat. Maka tidak heran jika music pop kontemporer ini menjadi sangat berpengaruh dikalangan masyarakat terutama kalangan remaja milenial. Pengaruh yang dimiliki oleh music pop kontemporer ini terjadi karena didalam music pop kontemporer mengandung nilai, norma dan jiwa rasa kemanusiaan yang besar. Misal seperti lagu yang berjudul Kita Kan Bisa yang dirilis oleh Kla Project pada Mei tahun 2020 yang berisi lirik semangat dalam mengajak setiap orang untuk bersama-sama sabar dalam melalui masa pandemic covid-19 ini. Tentu dari lagu yang dirilis oleh Kla Project membawa pengaruh besar untuk masyarakat yang tengah mengalami keresahan dan kehilangan pekerjaannya, hingga akhirnya dari lagu ini mereka mulai sadar dan bangkit dari keterpurukannya. Sebagaimana firman allah dalam Al-Quran surat Al-Insyiroh Ayat 6:

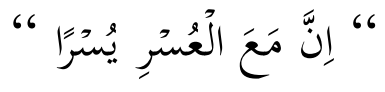

artinya : Sesungguhnya beserta kesulitan itu ada kemudahan. ${ }^{7}$ Dan juga firman allah dalam surat Al-Baqarah ayat 286:

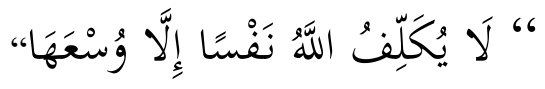

artinya: Allah tidak akan membebani seseorang melainkan sesuai kesanggupannya. Tidak hanya lagu dari Kla Project saja namun dari beberapa lagu lainnya juga mengandung nilai islam yang membuat mereka sadar.

\footnotetext{
${ }^{7}$ Al-qur'an, Surah Al Insyiroh Ayat 6, juz 30. Hal 596.
} 
Tidak diragukan lagi bahwa music pop kontemporer ini telah merajai hiburan ditanah air dan dunia sampai detik ini. Banyak orang sukses dimasa mudanya karena menjadi orang terkenal dan banyak uang karena sebuah music yang mereka cover atau mereka buat. bahkan para dai sekalipun yang berawal untuk menyampaikan dakwah islam saja saat ini membuat music sebagai tuntutan professional praktis dan ekonomis yang dapat menghasilkan keuntungan materi, emosional dan social. Seorang dai sebagai individu juga merasakan bahwa pengaruh yang dibawa oleh music kontemporer ini dapat digunakan sebagai media dakwah yang bisa dinikmati oleh siapapun terutama kalangan remaja milenial yang setiap waktunya music menjadi suatu kebutuhan manusianya. Misalnya seperti pesan dakwah yang terkandung dalam lagu Sabyan Gambus mengenai lagu-lagu yang bertema nilai islamnya.

Seorang dai adalah panutan dan pembimbing umat, bukan hanya bagian dari dirinya sendiri namun untuk masyarakat kecil seperti keluarganya dan beberapa orang terdekatnya. Dai sudah menjadi bagian dari umat dan bagian dari masyrakat. Untuk itu perlu seorang dai mengetahui apa yang menjadi pengaruh dalam music pop kontemporer ini agar tiap dai bisa mengimplementasikan music pop kontemporer ini dalam nilai islam. Perihal music pop, semiotikus mazhab Frankfurt Theodor Adorno dalam esainya yang sangat berpengaruh $\mathrm{On}$ Populer Music dikutip oleh Jhon Storey dalam Acep Aripuddin yakni "membuat tiga pernyataan spesifik tentang music pop. Pertama, kata Adorno adalah music pop "distandardisasi", yaitu meluas mulai segi-segi umum hingga segi-segi yang paling khusus sekali. pola music atau lirikan sukses, ia diekspliotasi hingga mengalami kelelahan komersial yang memuncak dan sampai pada kritalisasi standar. Kedua kata Adorno adalah music pop mendorong pendengaran pasif. Konsumsi music pop itu senantiasa pasif dan repetitive yang menegaskan dunia sebagaimana adanya. Ketiga kata Adorno adalah klaim bahwa music pop beroperasi seperti “konsumen social”. Fungsi social-psikologisnya adalah meraih penyesuain fisik dengan mekanisme kehidupan saat ini dalam diri konsumen music pop."8 Dari beberapa pernyataan yang disebutkan oleh adorno, maka pengaruh pada music kontemporer ini cukup besar. Seperti music dari Brian Adam music yang tergolong serius ini mampu membuat suatu pengaruh besar, yakni tiap liriknya dapat mengekspresikan keseluruhan. Tidak hanya itu, music pop kontemporer ini mampu membuat laki-laki dan perempuan menghilangkan rasa tegang ketika bekerja dikantor atau suatu pabrik. Maka dari itu upaya melakukan transmisi pesan nilai-nilai dalam islam melalui music itu dilakukan. Misal lewat nasyid ( lagu yang

${ }^{8}$ Acep Aripuddin (Jhon Storey), Cultural Studies Dan Kajian Budaya Pop, (Yogyakarta-Bandung: Jalasutra). Hal 42. 
mengandung nilai keislaman) dan beberapa lirik lagu pop yang mempunyai nuansa keagamaan. Sebagai contohnya syair Abu Nawas "I'tiraf" yang ada pada buku cerita yang berjudul Kisah 1001 Malam Abu Nawas Sang Penggeli Hati asal muasal syair tersebut ada. Syair tersebut semula popular hanya dikalangan para santri dan masyarakat di desa. Kemudian ketika masuk dalam nuansa music pop, lagu yang awalnya hanya dinyanyikan, digemari oleh para santri kini juga dimainkan oleh kalangan mahasiswa dan masyrakat kota.

Pergeseran nuansa dan lirik lagu dari klasik menjadi popular ini dapat mengambarkan bahwa pengaruh music pop kontemporer ini begitu besar. Karena adanya timbal balik dalam komunikasi publiknya. Pengaruh dalam music pop kontemporer ini tidak hanya berpengaruh baik saja, namun ada beberapa pengaruh buruk yang terjad pada remaja milenial. Menurut pendapat Paddy Whanel (1964) "menegaskan bahwa potret anak muda sebagai orang lugu yang dieksploitasi oleh industry music pop terlalu disederhanakan". ${ }^{9}$ pernyataan Paddy tadi mengungkap bahwa apakah remaja milenial ini dapat membantu memperlihatkan pemahaman nilai-nilai dalam islam, karena menurut Paddy music pop kontemporer ini lebih ke ranah hiburan remaja milenial, dimana lagu-lagu pop yang mereflesikan kesulitan yang dialami remaja milenial dalam menghadapi kekusutan persoalan emosionalnya dan beberapa lagu pop kontemporer ini lebih mengekspresikan stimuli akan keamanan di dunia emosional yang tidak pasti dan selalu berubah-ubah. Apabila dianalisis secara keseluruhan bahwa pengaruh music pop kontemporer ini memiliki pengaruh baik dan buruknya yang sama-sama menantang. Inilah yang menjadi upaya seorang dai untuk terus mampu menulis dan mendendangkan music pop kontemporer dengan mengikuti dimensi psikologi, religo dan sosiologis masyarakat terutama para remaja milenial. Agar berkurangnya pengaruh buruk dan dapat melahirkan nasyid-nasyid pop religious.

Mari kita renungkan sejenak, dari sekian animo manusia, dunia remaja milenial khususnya, bagaimana kira-kira jika mengisi dunia music pop kontemporer itu dengan pesanpesan islam yang menarik para remaja milenial. Seperti ketertarikan para remaja milenial pada lagu-lagu pop barat pada umumnya. Tablig melalui music pop ini merupakan strategi dakwah efektif yang membuat manusia berirama dan mensyairkan tentang nilai islam, tentang kemajuan, tentang masa depan terakhir (akhirat), dan tentang kehidupan sesungguhnya yang tidak menerobos dinding syariat islam. Penanaman serta pemahaman mental seperti ini tentu sangat urgen untuk kita mulai lakukan saat ini. Sebagai contoh, akan banyak komponiskomponis yang menulis lirik-lirik islami dalam beberapa karya musicnya.

\footnotetext{
${ }^{9}$ Acep Aripuddin (Paddy Whanel), Cultural Studies, ibid (Bandung:PT Rosdakarya Offset). Hal 57
} 
Kecenderungan manusia saat ini dalam dunia dakwah membawa pengaruh dan menyeret unsur sosialnya, untuk itu perlu setiap dai harus terampil dan cerdas dalam tiap saluran-saluran sebagaimana digandrungi oleh budaya masyarakat saat ini. Jika dai tidak mempunyai elemen budaya pop, tentu tidak akan bisa untuk mempengaruhi para remaja yang sudah mempunyai ketertarikan dalam music pop kontemporer. Oleh karena itu, perlu dilakukan oleh dai menggunakan saluran-saluran music pop kontemporer tersebut sebagai saluran penyampaian pesan-pesan islam secara efektif. Menjadi dai pop, yang menggunakan saluran music pop sebagai media penyampaian pesan-pesan islam beserta syariat dan nilai yang melingkupinya. Kepada muslim pemula (mualaf) tidaklah tepat jika seorang dai tidak menggunakan saluran music pop untuk mengenalkan islam, sebagaimana yang kita tahu bahwa orang non muslim yang ibadahnya dengan selalu mendendangkan music.

\section{Problematika Musik Pop Kontemporer Dalam Dakwah Islam}

Menurut pendapat Daryanto "Problema berasal dari kata problem yang punya arti suatu permasalahan, perkara sulit, dan persoalan. Pendapat dari sumber lain juga dikemukakan bahwa problem berarti soal, masalah".10 Sedangkan menurut pendapat Prof. moh. Ali Aziz, M.Ag. " pengertian problematika menurut istilah adalah permasalahan yang muncul dalam menyeru, memanggil, mengajak dan menjamu, dengan proses yang ditangani oleh para pengembang dakwah".11 Sejak generasi milenial saat ini, semakin banyak orang yang berbondong-bondong untuk menyampaikan pesan-pesan islam melalui dunia music pop kontemporer. Boleh jadi, para dai yang memiliki bakat dalam musik mampu menggerakkan masyarakat menuju jalan Allah SWT. Karena dalam tahapan awal dakwah, kita memerlukan orang yang mampu membuat kita yakin tentang ajaran islam. Dan ini termasuk kunci sukses dakwah, bahwa pendakwalah yang membukakan pintu gerbang ajaran agama islam. Namun, disisi lain semakin banyaknya konsumen yang menggunakan music pop kontemporer ini, maka akan semakin banyak pula problema-problema yang terjadi pada music pop kontemporer. Karena mulanya konsumen yang sedikit itu memperkecil suatu problema, namun jika konsumennya lebih banyak maka semakin besar pula problema yang harus di hadapi.

Mengambil dari satu problema yang membuat efek negative bagi tiap individu atau organisasi. Beberapa bulan yang lalu problema yang di alami oleh penyanyi religi "Sabyan Gambus" ini begitu hangat diperbincangkan disocial media, karena hubungan terlarang Nissa

\footnotetext{
10 Daryanto, Kamus Bahasa Indonesia Lengkap, (Surabaya:Apollo). Hal 490.
}

${ }^{11}$ Prof. Moh. Ali Aziz, M.Ag, Ilmu Dakwah, ( Jakarta:Rajawali Pers). Hal 113. 
Sabyan dengan Ayus (keybordis di sabyan gambus) membawa dampak negative ke musisi religi. Diambil dari berita "TRIBUNNEWSMAKER.COM pada tanggal 29 mei 2021. Awal mula perselingkuhan nissa sabyan dan ayus terbongkar mngenai cinta segitiga mereka. Yang awal mulanya kabar perselingkuhan ini mencuat setelah adanya konten terkait kisah mereka berdua di aplikasi tiktok, ditambah lagi ada unggahan tangkapan layar dari Pengadilan Agama Jakarta Utara di sebuah akun gossip. Dari data tersebut, diketahui bahwa Ririe Fairus (Eri Fitriyani) menggugat cerai sang suami (Ayus)." Dan juga dari video yang diterima oleh Kompas.com pada Minggu tanggal 21 februari 2021 " dari unggahan video tersebut ayus buka suara perihal isu problema perselingkuhan dengan Nissa. "kata Ayus : Saya dengan penh kesadaran dan ketulusan ingin memohon maaf kepada istri, keluarga, teman-teman Sabyan, dan semua yang merasa tidak nyaman dengan kekhilafan yang saya lakukan." Mengenai problem ini mungkin akan berdampak besar bagi kalangan public yang sudah lama tertarik dengan dakwah music oleh grub band Sabyan Gambus. Karena ada Perasaan kecewa yang disampaikan oleh netizen dalam komentar-komentar pahit di akun Instagram Nissa Sabyan.

Dalam Hadist yang diriwayatkan oleh muslim (1988, II: 227: 170) dari Tsauban, Nabi SAW bersabda, "diantara umatku selalu ada kelompok yang menegakkan kebenaran. Orang yang membenci mereka tidak dapat memberikan bahaya kepada mereka. Hingga datangnya keputusan Allah mereka pun seperti itu".12 Dari mana pun berada, kapan pun waktunya dan bagaimana pun keadaanya seorang pendakwah akan selalu hadir untuk memepelajari ajaran islam sekaligus memperkenalkannya kepada masyarakat. Seorang pendakwah muslim menjadikan islam sebagai agamanya, dan alquran menjadi pedomannya. Karena sebagai pendakwah (pemimpin) adalah pemimpin bagi dirinya dan orang lain. Jika pemimpin yang disampaikan itu sesuai yang diperintahkan Allah maka wajib kita taati.

Ada sebuah mahfuzat ( kalimat mutiara) yang sudah banyak orang memakainya dalam aktivitas dakwah ataupun kehidupan sehari-hari . mahfuzat ini terindikasi dari sebuah hadist tentang setan yang mencuri Baitull Maal. Mahfuzat tersebut seperti ini.

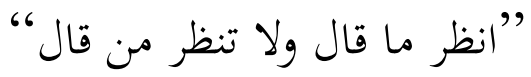

yang Artinya " Lihat apa yang disampaikan, namun jangan lihat siapa yang menyampaikan". Dari mahfuzat tadi kita bisa mengambil suatu kesimpulan yang terkait dengan problem dakwah. Berdakwah melalui music yang tiap lirik yang ia buat atau cover membuat para public terenyuh dan kembali ke jalan-Nya. Setiap manusia tentu tak luput dari

12 Prof. Dr. Moh. Ali Aziz, M.ag. Ilmu Dakwah, Kualifikasi Dakwah, (Rawamangun:Jakarta). Hal 186. 
kesalahan dan dosa yang mereka perbuat entah itu sengaja ataupun tidak di sengaja, karena manusia adalah makhluk Allah yang istimewa yang mempunyai hawa nafsu. Untuk itu jika problem ini membuat masyarakat menjadi membenci pihak kasus atau tidak mau lagi untuk mendengarkan dakwahnya maka kembalilah dan ingatlah jika tiap manusia punya maqom (tempat) salahnya masing-masing. "Tiap apa yang dibicarakannya benar maka lakukan dan ikutilah jalan menuju surga-Nya, jangan melihat perbuatan dosa dan kesalahannya". Pengaruh era globalisasi yang mulai merasuki organ-organ psikis-behavioral masyarakat Indonesia terutama para remaja milenial yang memunculkan problema-problema serta tantangan dakwah yang semakin padan. Baik dari factor internal yang terjadi pada organ tubuh umat islam yang dilatar belakangi oleh kebodohan, kemalasan dalam mencari ilmu serta ketidakmampuan mereka, dan juga dari factor eksternal yang terjadi pada social media dan lingkungan tempat berinteraksi setiap harinya. tantangan pun muncul dari berbagai bentuk kegiatan yang dilakukan masyarakat modern seperti missal perilaku mereka dalam mendapatkan euphoria, fashion, seni dan sebagainya. Yang membuat peluang munculnya suatu problem moral dan etika yang sifatnya terbuka dalam bentuk kemaksiatan. Adanya berbagai problema, permasalahan, hambatan serta tantangan dari eksternal atau internal merupakan suatu bagian yang tidak akan terpisahkan oleh perjuangan menyampaikan dakwah dalam ajaran islam. Karena itu sudah menjadi salah satu sunnatullah bagi setiap umat islam untuk menyampaikan kebenaran. Maka dari mengenali, memahami, dan memperhatikan problemproblem dakwah tersebut merupakan bentuk penting untuk mencapai suatu keberhasilan dalam berdakwah.

Dengan demikian, problem pada music pop kontemporer ini menjadi salah satu contoh problematika dalam dunia remaja milenial, perlu adanya pendekatan dakwah structural yang professional, mengingat bahwa remaja milenial potensi nilai islamnya yang masih terbatas, sementara kita dituntut untuk mengakomodasi permasalahan yang muncul pada tiap budaya pop yang berkembang pesat. Mendakwahkan islam memiliki arti memberikan solusi atau jawaban terhadap berbagai permasalahan umat islam. Oleh karena itu, dakwah islam akan selalu dipanggil untuk menyelesaikan persoalan masalah yang sedang terjadi dan akan dihadapi oleh umat islam. Meskipun dari pengertian dakwah sendiri yakni berarti mengajak atau menyeru ke jalan islam, namun tantangan dakwah yang berupa probmlematika umat manusia ini masih menjadi salah satu misi dakwah untuk menuju jalan yang benar.

Sukses dalam berdakwah bukan dilihat dari riuhnya mad'u, gelak tawa mereka atau tangisan mereka. Kesuksesan dalam dakwah dapat kita lihat dan rasakan dari bekas yang 
mad'u tinggallkan dalam benak hatinya atapun tercermin dari sikap perilaku seorang mad'u yang menjadi lebih baik dari sebelumnya dan tertanam suatu kenyakinan serta mengamalkan keimanan dan syariah islamiyyahnya pada tiap waktunya. Namun bukan tugas kita memakasakan kehendak mereka merubah moral atau etika, tetapi itu semua dari Allah SWT sang pembolak balik hati hambanya yang mana sudah dijelaskan pada Al- Quran surat AlImron ayat 8 Allah Berfirman:

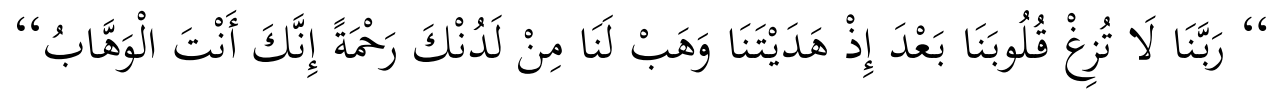

Artinya: (mereka berdoa) Ya Tuhan kami, Janganlah engaku condongkan hati kami kepada kesesatan setelah engkau berikan petunjuk kepada kami, dan karuniakanlah kepada kami rahmat dari sisi-mu, sesungguhnya Engkau Maha Pemberi”. ${ }^{13}$

Sebagai pendakwah cukup ikhtiyar selanjutnya bertawakal (berserah diri) kepada Allah SWT. Hasil akhirnya tergantung dengan Allah SWT yang memberikan rahmat pada tiap hamba yang Allah kehendaki. Dan dari Rasulullah SAW yang selalu memberi syafaat umatnya hingga kelak di hari kiamat.

\section{PENUTUP}

Berdasarkan pembahasan artikel konseptual di atas, maka dapat ditarik benang merah sebagai berikut:

Perkembangan islam yang semakin modern menuntut relevansi media dakwah dan konteksnya agar ajaran agama islam bisa "Sahih likulli zaman wa makan" yang artinya "Benar Setiap Waktu Dan Tempat". Untuk itu perlu media dakwah atau sarana dakwah yang mengikuti pasar mudanya. Music pop kontemporer inilah yang menjadi salah satu media dakwah di Indonesia yang banyak sekali konsumen dan yang memproduksinya, meskipun dikala pandemic covid-19 yang tidak tahu ujung penyelesaiannya ini tidak menghalangi seni music pop kontemporer tetap up to date dalam mensyiarkan nilai-nilai ajaran islam. Bahkan dari music pop kontemprer ini membuat masyarakat tidak dilema atau putus asa dalam menghadapi situasi serius (pandemic covid-19) ini. missal music dari band Sabyan Gambus yang berjudul "Sapu Jagat” yang baru-baru ini dirilis yang dalam liriknya "Berserahku padaNya 'tuk menggapai semua, yakinku cara-Mu lah.." dari lirik ini yang membuat masyarakat milenial semakin tergugah dirinya untuk sabar dan tetap dijalan-Nya. Begitu besar pengaruh

${ }^{13}$ Al-quran, Surat Al-imron Ayat 8, juz 3. Hal 50. 
dari music pop kontemporer dalam dunia dakwah terutama pada pasar mudanya. Meskipun problema dakwah yang sedang dhadapi tidak mudah, perlu dari diri kita untuk selalu memperjuangkan nilai islam dalam budaya pop manapun. Karena ajaran islam ini lebih tinggi dari pada kebenaran yang disampaikan pada rasional manusia.

\section{DAFTAR PUSTAKA}

Al- Qur'an (Kitab Suci)

Amin, Ilmu Dakwah, (Jakarta: Kencana).

Arthur Danto, After The End Of Art, ( Princeton University Press:Amerika Serikat).

Acep Aripuddin (Paddy Whanel), Cultural Studies, ibid (Bandung:PT Rosdakarya Offset).

Daryanto, Kamus Bahasa Indonesia Lengkap, Surabaya, Apollo, 1997.

Djojosudarmo, Maryanto, Apresiasi Karya Seni Modern dan kontemporer, (Jakarta: Balai Pustaka).

https://newsmaker.tribunnews.com/2021/02/19/kronologi-awal-mula-nissa-sabyankepergok-selingkuh-istri-sah-ayus-sudah-firasat-sempat-memaafkan

Jhon Storey (dalam Acep Aripuddin sosiologi Dakwah) Cultural Studies dan Kajian Budaya Pop, (Yogyakarta-Bandung:Jalasutra).

Prof. Dr. Moh. Ali Aziz, M.ag. Ilmu Dakwah, Kualifikasi Dakwah, (Rawamangun-Jakarta).

Setiadi, Gatut, and Nurma Yuwita. "PENGEMBANGAN MODUL MATA KULIAH BAHASA INDONESIA MENGGUNAKAN MODEL ADDIE BAGI MAHASISWA IAI SUNAN KALIJOGO MALANG". Akademika : Jurnal Manajemen Pendidikan Islam 2, no. 2 (December 3, 2020): 200-217. Accessed May 2, 2021. https://ejournal.iaiskjmalang.ac.id/index.php/akad/article/view/207.

Yosepha Pusparisa, Analisis Data "Wajah Baru Industri Musik Di Era Digital”, 21 Desember 2020, 11.28 WIB. 